\title{
Sambandet mellan egenmakt och välbefinnande
}

Susanne Jungerstam och Maj-Helen Nyback

\section{ABSTRAKT}

Begreppet egenmakt, översatt från det engelska ordet empowerment, bottnar i individers och kollektivs möjligheter och förmåga att påverka sin omgivning i frågor som upplevs som viktiga. Egenmakt kan betraktas som en metod eller som ett medel, men det kan också utgöra ett mål i sig självt. Välbefinnande är i sin tur nära kopplat till tillfredsställelse med livet, välmåga och välfärd. Genom denna granskning strävar vi efter att generera en tvärvetenskaplig syn på de två närliggande, men ändå distinkta begreppen egenmakt och välbefinnande. Vår avsikt är att visa på begreppens betydelse $i$ en interdisciplinär kontext, där både de hälso- och samhällsvetenskapliga förståelserna av de båda begreppen kan fördjupas genom interdisciplinär förståelse. Granskningen utmynnar i en referensram som syftar till att belysa hur de olika begreppen egenmakt och välbefinnande sammanhänger, samt hur några av de resursfaktorer som ofta lyfts fram i anslutning till de båda termerna samverkar med begreppen.

Nyckelord: egenmakt, välbefinnande, interdisciplinär ansats 


\section{ABSTRACT \\ THE RELATIONSHIP BETWEEN EMPOWERMENT AND WELLBEING}

- The concept of empowerment may be seen either as a method, a mean of achieving greater power or control, or as a goal in its own right. Wellbeing, on the other hand, is frequently connected to wellness and satisfaction with life. In this article we aim at generating an interdisciplinary understanding of the two closely related, yet distinct concepts, empowerment and wellbeing. Our intention is to portray the concepts both from a caring science and a social sciences point of view. Therein, the article generates an interdisciplinary frame of reference elucidating how the two concepts are associated, including some of the resource factors that are frequently shown to be associated with the concepts of wellbeing and empowerment.

Key words: empowerment, wellbeing, interdisciplinary approach

\section{Bakgrund}

nom socialpedagogiken kombineras det sociala och det pedagogiska perspektivet. Förenklat kan vi säga att socialpedagogiken i Finland utvecklats utgående ifrån två utvecklingslinjer, den ena förankrad i social omsorg och välbefinnande med syfte att förebygga och lindra social exkludering, och den andra med fokus på att främja individuell tillväxt och växande inom ramen för en större gemenskap och ett aktivt medborgarskap (Hämäläinen 2012a, 5). I ett bredare perspektiv har socialpedagogiken fokuserat på teorier och metoder som stöder människor i att uppnå deras fulla potential. Härvidlag uppvisar socialpedagogiken vissa likheter med socialt arbete, varvid ett sätt att definiera skillnaden mellan socialpedagogik och socialt arbete är att ta fasta på att det sociala arbetet framför allt fokuserar på att förebygga och lindra utsatthet och social exkludering, medan socialpedagogiken berör många olika grupper, även grupper som inte är riskgrupper för utsatthet (Nivala 2019, 6).

I och med ovanstående ter sig ämnesområdets koppling till flera samhällsvetenskapliga discipliner, inklusive socialt arbete och socialpolitik, som tämligen uppenbara. Hämäläinen $(2012 b, 97)$ skriver också att arbete som strävar efter att förebygga social och utbildningsmässig exkludering, samt främja välbefinnande, förutsätter att socialpolitik och socialpedagogik 
går hand i hand både i teori och praktik. Socialpedagogikens koppling till hälsovetenskapliga discipliner, inklusive vårdvetenskap, ter sig dock betydligt mera svårfångad.

Denna granskning syftar till att lyfta fram två begrepp som ofta hänvisas till inom såväl socialpedagogik som samhällsvetenskaper och hälsovetenskaper: egenmakt (empowerment) och välbefinnande. Målsättning är att generera en tvärvetenskaplig förståelse för hur de två närliggande men ändå distinkta begreppen sammanhänger. Detta gör vi med stöd av fyra resursfaktorer som ofta lyfts fram i anslutning till de båda termerna: hälsa, aktivitet, ekonomi och socialt sammanhang. Här fokuserar vi på resursfaktorerna i deras individuella bemärkelse. Genom denna granskning är vår avsikt att visa på begreppens betydelse i en interdisciplinär kontext, där både de hälso- och socialvetenskapliga förståelserna kan fördjupas medelst en interdisciplinär förståelse.

\section{Egenmakt}

I svenskspråkig litteratur används ofta begreppet egenmakt som en översättning av begreppet empowerment. Egenmakt är emellertid ett tämligen omtvistat begrepp, dels p.g.a. att det är mera begränsat än begreppet empowerment, och dels p.g.a. dess likhet med ordet egenmäktig som används i en helt annan bemärkelse än egenmakt. Därtill saknar det svenska ordet egenmakt en verbform, varvid to empower oftast översätts till att "befullmäktiga" eller "bemyndiga" som båda används frekvent i helt andra sammanhang. Inte heller på finska finns någon entydig motsvarighet till empowerment. Ryynänen och Nivala $(2017,35-36)$ lyfter fram begrepp som valtautuminen, voimaantuminen samt voimavaraistuminen, som dock bottnar i något olika betoning av de element som inkluderas i empowerment.

Trots ovanstående problematisering av de olika översättningarna av ordet empowerment som föreligger, kommer vi i det följande att använda oss av egenmakt i samma betydelse som det engelska begreppet empowerment.

De tidiga definitionerna av begreppet egenmakt strävade efter att fånga begreppets multideminsionalitet. Med multidimensionalitet avsågs begreppets olika psykologiska, sociala och politiska komponenter (t.ex. Rogers, Ralph \& Salzer 2010, 933). Därtill har många definitioner lyft fram individens förmåga att utöva kontroll över sitt eget liv, varvid en bredare förståelse av begreppet utvecklats. 
Flera ansatser har betonat begreppets betydelse på olika nivåer, varav t.ex. Bakker och van Brakel $(2012,130)$ beskriver begreppet på både en individuell, organisations- och samhällsnivå. På individnivå formulerar Huyung Hur $(2006,535)$ egenmakt som ett tillstånd av befrielse som är tillräckligt starkt för att inge en person en känsla av makt i livet, gemenskapen och samhället. Huyung Hur förstår således egenmakt som ett tillstånd, eller ett mål, i sig självt.

Inom den finländska socialpedagogiska traditionen avser begreppet egenmakt på individnivå oftast utvecklingen av en inre styrka, samtidigt som egenmakt inom socialt arbetet ofta relaterar till resursförstärkande arbetssätt eller metoder (Ryynänen \& Nivala 2017, 36-38). Abbot, Wallace och Sapsford (2016) betonar också flertalet olika element som krävs för att uppnå det tillstånd av delaktighet och självbestämmanderätt som kännetecknar egenmakt, vilket i sin tur utgör grund för att betrakta egenmakt som ett medel.

Utgående från ett hälsovetenskapligt perspektiv kan egenmakt ses som en process genom vilken människan får större kontroll över beslut och åtgärder som framför allt har betydelse för individens hälsa (Nutbeam 1998, 354). I en vårdkontext definierar WHO egenmakt som en process genom vilken patienten förstår sin roll och erhåller kunskap och färdigheter att delta i och kontrollera de beslut som påverkar hens hälsa, eller mera specifikt som "[a] process in which patients understand their role, are given the knowledge and skills by their health-care provider to perform a task in an environment that recognizes community and cultural differences and encourages patient participation" (WHO 2009, 190).

Begreppet egenmakt används även i sammanhang där avsikten är att stärka vårdares moraliska och etiska förhållningssätt (Khoshmehr, Barkhordari-Sharifabad, Nasiriani \& Fallahzadeh 2020; Travers, Schroder, Norful \& Aliyu 2020). Ny forskning visar att begreppet egenmakt kan användas för att beskriva utvecklingen av strukturella system som möjliggör en vårdares välbefinnande (Roji \& Jooste 2018). På den individuella nivån utgår förståelsen dels ifrån vårdsökandes möjlighet att påverka vården, och dels ifrån både vårdgivares och vårdtagares möjligheter att påverka vården på individ- och organisationsnivå, och samtidigt stärka patientens och vårdarens relation (Mudiaga \& Elohor 2018).

Mångfalden av förståelser av begreppet egenmakt har lett till att det finns ett stort antal mätmetoder och mått på egenmakt. Förståelsen av begreppet försvåras av att de olika måtten mäter olika aspekter på olika 
nivåer, vilket gör att de sällan är helt jämförbara. (Cyril, Smith \& Renzaho 2016.)

Sammanfattningsvis kan sägas att egenmakt både kan betraktas som en metod, ett medel, verktyg eller instrument, och som ett mål i sig självt. Fokus i det förra fallet ligger vid stärkande av de resurser som bidrar till att skapa och upprätthålla egenmakt som ett medel eller en strategi för att uppnå förändring och en högre grad av välbefinnande i olika kontext. I det senare fallet ses egenmakt som ett uttryck för en individuell känsla av att vara stark och inflytelserik i frågor som är viktiga för personen, gemenskapen eller för samhället i stort. Därtill kan egenmakt betraktas som ett verktyg som möjliggör eller stärker en vårdares färdighet och välbefinnande i arbetet.

\section{Välbefinnande}

Oxford Living Dictionaries (n.d.) definierar välbefinnande (wellbeing) som "the state of being comfortable, healthy, or happy", fritt översatt till ett tillstånd av att känna sig tillfreds, ha hälsa och vara lycklig. Likt egenmakt är välbefinnande ett begrepp som används inom många olika discipliner. Ofta används välbefinnande parallellt eller synonymt med andra begrepp, varvid tillfredsställelse med livet och välmåga hör till de oftast förekommande förståelserna. Därtill är det inte ovanligt att välbefinnande likställs med välfärd, livskvalitet och lycka. Med social välfärd avses dock oftast levnadsnivån på samhällsnivå, varvid subjektivt välbefinnande utgör ett mått på politikens utfall tillsammans med flera andra (Nygård 2013).

Till skillnad från ovanstående inkluderar Eriksson (2018) välbefinnande i sin definition av hälsa. Eriksson öppnar upp för att hälsan är föränderlig i tid och rum och avspeglar såväl en objektiv som en subjektiv dimension. Hälsodimensionen kommer till uttryck i friskhet, sundhet och välbefinnande. Friskhet bottnar i fysisk hälsa, såväl den objektivt mätbara som den subjektivt upplevda, medan sundhet fokuserar på en individs möjlighet att vara inkluderad i samhället och ha förmåga att själv fatta beslut som berör den egna hälsan. Välbefinnande förstås som individens subjektiva upplevelse av sin situation, varvid hälsa inte endast är avsaknaden av sjukdom. Den objektiva dimensionen kommer till uttryck i det som objektivt kan mätas.

Enligt Prasoon och Chaturvedi (2016) återspeglar mycket av den befintliga forskningen om välbefinnande och tillfredställelse med livet 
både hur väl en individs basbehov är fyllda och hur långt övriga mål i livet (både långsiktiga och kortsiktiga) kan betraktas som uppnåeliga.

Ser vi till evaluering av och mätmetoder för välbefinnande har Lindert, Bain, Kubzansky och Stein (2010) funnit 60 unika skalor för att mäta välbefinnande. Bland de oftast förekommande faktorerna som inkluderades finns hälsa, sociala relationer och tillfredsställelse med livet. Inom samhällsvetenskaperna baserades mätningar och jämförelser ofta på storskaliga undersökningar som även inkluderar frågor om lycka, ekonomi och aktivitet (jfr t.ex. European Social Survey Database 2015). Linton, Dieppe och Medina-Lara (2016) lyfter i sin tur fram 99 olika mätinstrument som sammanlagt inkluderar 196 dimensioner som avser mäta välbefinnande, inklusive fysiskt, mentalt och socialt välbefinnande, aktiviteter och personliga omständigheter. De förstnämnda är ofta kopplade till en mera generell förståelse av hälsa, medan den sistnämnda dimensionen även inkluderar ekonomiskt välbefinnande.

\section{Resursfaktorer för egenmakt och välbefinnande}

Gemensamt för förståelserna av egenmakt och välbefinnande är att de inkluderar flertalet underliggande faktorer som antingen förklarar eller bidrar till både egenmakt och välbefinnande. Särskilt faktorerna hälsa, ekonomi, aktivitet och social samhörighet förekommer ofta i de båda förståelserna av begreppen, och i de olika mätmetoder som egenmakt och välbefinnande baseras på. Ytterligare finns det rikligt med studier som visar på faktorernas inbördes samband.

\section{Hälsa}

Hälsa förekommer inom flera discipliner, även om tolkningen av hälsa och hälsans betydelse varierar beroende på sammanhang och disciplin. T.ex. Abbot et al. (2016) beskriver hälsa som den grundläggande resursen utan vilken vare sig ekonomi eller politik skulle fungera, samtidigt som författarna inkluderar hälsa i förståelsen av egenmakt på samhällsnivå. WHO inkluderar däremot välbefinnande som en dimension i en överordnad förståelse av hälsa. Denna är baserad på WHO:s 1948års konstitution, där hälsa definierades som ett tillstånd av fullständigt fysiskt, mentalt och socialt välbefinnande, inte endast som avsaknaden av sjukdom (WHO 1998, 1).

Eriksson (2018, 283-288) utgår å sin sida från en helhetssyn på människan och dennes tro på sin egen inneboende förmåga och individens 
behov av att känna att livet, existensen, har en mening. Eriksson beskriver den ontologiska modellen av hälsa som en rörelse från att göra (med fokus på hälsosamma vanor och förebyggande arbete) och att vara (med fokus på balans och harmoni) mot att varda, som innebär en djupare integration med livets betingelser. För att uppnå hälsa som vardande krävs att individen själv finner eller ser en mening $i$ att varda.

Hälsan är såväl mätbar som omätbar. Den mätbara hälsan utgörs av den objektiva synen på hälsa där t.ex. laboratoriesvar och prestationer utgör ett mått på hälsa och sjukdom. Den omätbara hälsan utgörs av den subjektivt upplevda situationen, varvid den omätbara hälsan kan förknippas med subjektivt upplevt välbefinnande (Gillett-Swan \& Sargent 2015; Eriksson 2018).

\section{Ekonomi}

Utöver hälsa ger flera studier vid handen att välbefinnande hänger samman med nationell ekonomisk tillväxt (Gillett-Swan \& Sargent 2015, 136; Tiwari 2009). Samtidigt höjer ekonomi i kombination med begränsat socialt kapital risken för svag hälsa (Ahnqvist, Wamala \& Lindstrom 2012). Samhällen som rankas högt i frågan om välbefinnande är ofta ekonomiskt utvecklade, har en fungerande förvaltning, förhållandevis lite korruption och kan svara mot invånarnas behov i frågan om mat och hälsa (Diener, Richard, Schimmack \& Helliwell 2009).

Ngamaba, Panagioti och Armitage (2017, 379-382) beskriver i sin litteraturgenomgång ett positivt samband mellan hälsa och subjektiv tillfredsställelse med livet, samt med upplevelsen av lycka. I merparten av de s.k. utvecklingsländerna finns dock ett starkare samband mellan fattigdom och hälsa än i de rikare länderna. World Value Survey (2018) visar även att höginkomstländer generellt sett rankas högre i frågan om subjektivt välbefinnande än länder med en lägre inkomstnivå.

Med avseende på egenmakt utgör ekonomisk egenmakt också en dimension av de fyra dimensioner av egenmakt som Abbot et al. (2016, 7880) lyfter fram, varvid ekonomisk egenmakt avser individens möjligheter att själv påverka hens arbetssituation och s.k. produktiva kapacitet.

\section{Aktivitet och samhällsengagemang}

Hagler, Hamby, Grych och Banyard (2016) visar att arbete främjar både välbefinnande och egenmakt. Välbefinnande främjas bl.a. genom att arbetet genererar inkomst (ekonomisk trygghet), samtidigt som det utgör 
en grund för autonomi och tillfredsställelse. Det sistnämnda har också ett samband med egenmakt i termer av stolthet i arbetet och kontroll (mastery).

Sambandet mellan frivilligarbete och hälsa är ävenså relativt väldokumenterat. Bl.a. Ho, You och Fung $(2012,320)$ finner att frivilligarbete är särskilt fördelaktigt för äldre personer som inte är engagerade i arbetslivet. Flera studier lyfter också fram betydelsen av frivilligarbete för den subjektiva upplevelsen av välbefinnande (Schulz, Schulte, Raube, Disouky \& Kandler 2018).

Utöver arbete associeras många andra aktiviteter med såväl välbefinnande, hälsa och social inkludering och civilt engagemang. Chan och Mak (2020) betonar betydelsen av samhällsengagemang för att uppnå ett större samhällsansvar och erhålla kontroll över resurser, institutioner och politik som påverkar individens liv och välfärd, nära kopplat till egenmakt.

\section{Socialt sammanhang}

Genom arbete och andra aktiviteter erhålles ett socialt sammanhang och social inkludering. På det individuella planet kan social inkludering inbegripa många olika relationer som erbjuder socialt stöd, trygghet och sociala nätverk. De sociala nätverken, ibland relaterade till i termer av socialt kapital, betraktas som viktiga för social inkludering, hälsa och välbefinnande. Samtidigt antas individuellt socialt kapital också öka tillgången till socialt stöd och inflytande. (Eriksson 2012; Nyqvist, Forsman, Giuntoli \& Cattan 2012.)

Betydelsen av social inkludering betonas i flertalet undersökningar som fokuserar på välbefinnande i olika miljöer (t.ex. Addae 2020; Saunders 2015). Den sociala inkluderingens motsats, ensamhet, har även ofta påvisats ha ett negativt samband med välbefinnande och hälsa, samt t.ex. med förmågan att hantera stress (Yadav \& Chadha 2017). Samtidigt visar t.ex. Cyril et al. (2016) på flera instrument som inkluderar socialt engagemang och socialt stöd i skalor som avser att mäta egenmakt.

\section{Hur relaterar begreppen egenmakt och välbefinnande till varandra?}

Utgående ifrån de definitioner, beskrivningar och förståelser av egenmakt och välbefinnande som redovisas här, finner vi att egenmakt i en finländska socialpedagogisk kontext ofta sammanhänger med arbetssätt 
och metoder om avser att utveckla egenmakt på individnivå. I ett interdisciplinärt sammanhang, med fokus på sambandet mellan egenmakt och välbefinnande, finner vi samtidigt att förståelsen av egenmakt har mycket gemensamt med förståelsen av välbefinnande, särskilt med avseende på vilka underliggande faktorer som antas ha ett samband med egenmakt och välbefinnande. Med stöd av en multidisciplinär kontext kunde förståelsen för båda begreppen vidareutvecklas.

Först och främst skiljer sig välbefinnande och egenmakt åt genom att egenmakt kan betraktas både som (1) ett tillstånd i sig självt och som (2) ett medel för att uppnå individens fulla potential. Välbefinnande kan däremot beskrivas relativt entydigt som ett eftersträvansvärt tillstånd (mål) i sig självt.

Ser vi till egenmakt som ett tillstånd finns det också fog att anta att egenmakt och välbefinnande är ömsesidigt beroende av varandra. Här kan vi anta att de olika resursfaktorerna uppskattas subjektivt som tillräckligt goda (inte nödvändigtvis som mycket goda) både hos de individer som upplever egenmakt och hos de individer som upplever ett subjektivt välbefinnande. Om egenmakt däremot betraktas som ett medel, eller ett verktyg, för att uppnå en individs fulla potential, utgör resursfaktorerna element som bidrar till processen. Fokus på resursförstärkande åtgärder bottnar följaktligen ofta i åtgärder som avser att förstärka de resurser som bidrar till att en individ utvecklar egenmakt, och i förlängningen till ett högre mått av välbefinnande.

Inom vårdområdet har egenmakt också kommit att inkludera strukturellt stöd för vårdaren i hens arbete. Detta synsätt tillför egenmaktbegreppet en för samhälls- och beteendevetenskaperna ny dimension, där de resursförstärkande åtgärderna inte enbart avser att stärka resurser hos patienter, klienter, brukare eller övriga användare. Egenmakt kan också fokusera på att stärka vårdarens etiska och moraliska förhållningssätt, varigenom hen kan uppnå välbefinnande i arbetet.

Utöver ovanstående kan egenmakt diskuteras på olika nivåer (individ, organisation och samhälle), medan välbefinnande oftast avser endast den individuella nivån. På samhällsnivå studeras välbefinnande oftare i termer av välfärd, även om välfärd indirekt inkluderar ett antagande om att välfärden inkluderar välbefinnande hos individerna som ingår.

Med avseende på resursfaktorerna som inkluderats i denna granskning noteras också att förståelsen av orsakssambandens riktning inte är entydig. Tidigare studier visar också på att innebörden av de olika 
resursfaktorerna är utarbetade inom flera olika discipliner, vilket medför en förenklad eller något ensidig förståelse t.ex. av hälsa inom beteendeoch samhällsvetenskaperna och av egenmakt inom hälsovetenskaperna. De olika disciplinerna har fortsättningsvis mycket att lära av varandra inom ramen för en multidisciplinär kontext där vi ser människan i ett holistiskt perspektiv.

\section{REFERENSER}

Abbot, P., Wallace, C. \& Sapsford, R. 2016. The decent society: planning for social quality. London, New York: Routledge.

Addae, E. A. 2020. The mediating role of social capital in the relationship between socioeconomic status and adolescent wellbeing: evidence from Ghana. BMC Public Health 20 (20), 2-11. DOI: https://doi.org/10.1186/s12889-019-8142-x.

Ahnquist, J., Wamala, S. \& Lindstrom, M. 2012. Social determinants of health - a question of social or economic capital? Interaction effects of socioeconomic factors on health outcomes. Social Science and Medicine 74 (6), 930-939.

Bakker, L. \& van Brakel, W. 2012. Empowerment assessment tools in People with Disabilities in Developing Countries. A systematic literature review. Leprosy Review 83, 129-153.

Chan, R. \& Mak, W. 2020. Empowerment for civic engagement and well-being in emerging adulthood. Evidence from cross-regional and cross-lagged analyses. Social Sciences and Medicine 244, 112703-112703. DOI: https://doi.org/10.1016/j.socscimed.2019.112703.

Cyril, S., Smith, B. J. \& Renzaho, A. M. N. 2016. Systematic review of empowerment measures in health promotion. Health Promotion International 31 (4), 809-826. DOI: https://doi.org/10.1093/heapro/dav059.

Diener E., Richard, L., Schimmack, U. \& Helliwell, J. 2009. Well-Being for public policy. New York: Oxford University Press.

Eriksson, M. 2012. Socialt kapital och hälsa - förklaringsmodeller och implikationer för hälsofrämjande interventioner. Socialmedicinsk tidskrift 4-5, 332-345.

Eriksson, K. 2018. Vårdvetenskap: vetenskapen om vårdandet - det tidlösa i tiden. Stockholm: Liber.

European Social Survey Database 2015. Measuring and Reporting on Europeans' Wellbeing: Findings from the European Social Survey. London: ESS Eric. Tillgänglig www.esswellbeingmatters.org (hämtad 30.10.2018).

Gillett-Swan, J. \& Sargeant, J. 2015. Wellbeing as a Process of Accrual: Beyond Subjectivity and Beyond the Moment. Social Indicators Research 121, 135-148. DOI: https:// doi.org/10.1007/s11205-014-0634-6. 
Hagler, M., Hamby, S., Grych, J. \& Banyard, V. 2016. Working for Well-Being: Uncovering the Protective Benefits of Work Through Mixed Methods Analysis. Journal of Happiness Studies 17, 1493-1510. DOI: https://doi.org/10.1007/s10902-015-9654-4.

Ho, Y. W., You, J. \& Fung, H. 2012. The moderating role of age in the relationship between volunteering motives and well-being. European Journal of Ageing 9, 319327. DOI: https://doi.org/10.1007/s10433-012-0245-5.

Hyung Hur, M. 2006. Empowerment in terms of theoretical perspectives: exploring a typology of the process and components across disciplines. Journal of Community Psychology 34 (5), 523-540. DOI: https://doi.org/10.1002/jcop.20113.

Hämäläinen, J. 2012a. Social Pedagogical Eyes in the Midst of Diverse Understandings, Conceptualisations and Activities. International Journal of Social Pedagogy 1 (1), 3-16. DOI: https://doi.org/10.14324/111.444.ijsp.2012.v1.1.002.

Hämäläinen, J. 2012b. Social Pedagogy in Finland. Kriminologija i socijalna integracija 20 (1), 95-104.

Khoshmehr, Z., Barkhordari-Sharifabad, M., Nasiriani, K. \& Fallahzadeh, H. 2020. Moral courage and psychological empowerment among nurses. BMC Nursing 19 (1). DOI: https://doi.org/10.1186/s12912-020-00435-9.

Lindert, J., Bain, P., Kubzansky, L. \& Stein, C. 2010. Well-being measurement and the WHO health policy Health 2010: systematic review of measurement scales. European Journal of Public Health 25 (4), 731-740. DOI: https://doi.org/10.1093/eurpub/ cku193.

Linton, M.-J., Dieppe, P. \& Medina-Lara, A. 2016. Review of 99 self-report measures for assessing well-being in adults: exploring dimensions of well-being and developments over time. BMJ Open 6 (7), e010641-e010641. DOI: https://doi.org/10.1136/ bmjopen-2015-010641.

Mudiaga, E. \& Elohor, A. 2018. Client Empowerment: A Concept Analysis. International Journal of Caring Sciences 11 (2), 743-750. Tillgänglig http://www.internationaljournalofcaringsciences.org/Issue.aspx?issueID $=48 \&$ pageIndex $=0$ \&pageReason=0 (hämtad 21.5.2021).

Ngamaba, K., Panagioti, M. \& Armitage, C. 2017. How strongly related are health status and subjective well-being? Systematic review and meta-analysis. European Journal of Public Health 27 (5), 879-885. DOI: https://doi.org/10.1093/eurpub/ckx081.

Nivala, E. 2019. Editorial: Special issue on social pedagogy in the Nordic countries. International Journal of Social Pedagogy 7 (1), 1-9. DOI: https://doi. org/10.14324/111.444.ijsp.2019.v7.1.011.

Nutbeam, D. 1998. Health Promotion Glossary, Health Promotion International 13 (4), 349- 364. Tillgänglig https://academic.oup.com/heapro/article/13/4/349/563193 (hämtad 30.9.2021).

Nygård, M. 2013. Socialpolitik i Norden. Lund: Studentlitteratur.

Nyqvist, F., Forsman, A., Giuntoli, G. \& Cattan, M. 2012. Social capital as a resource for mental well-being in older people: a systematic review. Aging \& Mental Health 17 (4), 394-410. DOI: https://doi.org/10.1080/13607863.2012.742490. 
Oxford Living Dictionaries (n.d.). Well-being. Oxford: Oxford University Press. Tillgänglig https://en.oxforddictionaries.com/ (hämtad 7.1.2019).

Prasoon, R. \& Chaturvedi, K. R. 2016. Life Satisfaction: A literature Review. The Researcher: International Journal of Management Humanities and Social Sciences 1 (2), 25-32.

Rogers, E. S., Ralph, R. \& Salzer, M. 2010. Validating the Empowerment Scale with a Multisite Sample of Consumers of Mental Health Services. Psychiatric Services 61 (9), 933-936. DOI: https://doi.org/10.1176/ps.2010.61.9.933.

Roji, G., \& Jooste, K. 2020. Perceptions of nurses on access to structural empowerment in a hospital in the Western Cape. Curationis 43 (1), e1-e9. DOI: https://doi. org/10.4102/curationis.v43i1.2018.

Ryynänen, S. \& Nivala, E. 2017. Empowerment or emancipation? Interpretations from Finland and beyond. Pedagogía Social. Revista interuniversitaria 30, 33-46. DOI: https://doi.org/10. SE7179/PSRI_2017.30.03.

Saunders, P. 2015. Social inclusion, exclusion, and well-being in Australia: meaning and measurement. Australian Journal of Social Issues 50 (2), 139-157.

Schulz, P., Schulte, J., Raube, S., Disouky, H. \& Kandler, C. 2018. The Role of Leisure Interest and Engagement for Subjective Well-Being. Journal of Happiness Studies 19, 1135-1150. DOI: https://doi.org/10.1007/s10902-017-9863-0.

Tiwari, M. 2009. Poverty and Wellbeing at the 'Grassroots' - How Much is Visible to Researchers? Social Indicators Research 90 (1), 127-140. DOI: https://doi.org/10.1007/ s11205-008-9316-610.1007/s11205-008-9316-6.

Travers, J., Schroder, K., Norful, A. \& Aliyu, S. 2020. The influence of empowered work environments on the psychological experiences of nursing assistants during COVID19: a qualitative study. BMC Nursing 19. DOI: https://doi.org/10.1186/s12912-02000489-9.

WHO 1998. Health promotion glossary. Geneva: World Health Organization. Tillgänglig https://www.ncbi.nlm.nih.gov/books/NBK144022/ (hämtad 21.5.2021).

WHO 2009. WHO Guidelines on Hand Hygiene in Health Care. Geneva: World Health Organization. Tillgänglig https://www.ncbi.nlm.nih.gov/books/NBK144013/pdf/ Bookshelf_NBK144013.pdf (hämtad 21.5.2021).

World Value Survey 2018. Subjective well-being rankings of 82 societies. Tillgänglig http://www.worldvaluessurvey.org/AJPublications.jsp?CndPUTYPE=2\&PUID=59 (hämtad 19.1.2020).

Yadav, V. \& Chadha N. K. 2017. Loneliness and its correlate: A literature review. Indian Journal of Health and Well-being 8 (8), 792-794. 